\title{
The Effects of Wall Color on Students' Attention Levels: An International School's Perspective
}

\author{
Chiharu Ogita ${ }^{1}$ and Ms. Amy Pothong ${ }^{1}$ \\ ${ }^{1}$ Nakornpayap International School, Chiang Mai, Thailand \\ DOI: https://doi.org/10.47611/jsrhs.v10i2.1418
}

\section{$\underline{\text { ABSTRACT }}$}

The aim of this study was to investigate the psychological impact of colored classroom walls on individuals. The research was conducted with eighth-grade students from an international school in Chiang Mai, Thailand. A total of 34 students with a variety of cultural backgrounds participated in this study. Students attended their regular classes with the three wall colors of purple, green, and red, while the Bourdon Attention Test was utilized as an assessment of the students' attention level. Data from the two conditions, control and experimental groups, each consisting of both pre-test and post-test, were collected and examined to find out the effects of different wall colors on the student's attention. The results indicate that the classroom with red-colored walls showed a significant impact on the participant's attention. In summary, this paper will contribute to enhancing awareness of how wall colors in educational facilities affect student's learning activity as well as to assist future designer's decisions on the usage of appropriate colors.

\section{Introduction}

Physical elements of an interior space stimulate human functions. Conditions in the environment may enhance or even interfere with the abilities of individuals in school, work, or at home (Maxwell, 2010, in Marchand, Nardi, Reynolds, $\&$ Pamoukov, 2014). In fact, according to the International Association of Color Consultants - North America, a school environment has a powerful impact on students, both psychologically and physiologically (Infrastructure Solutions Group, 2013). People spend most of their childhood in facilities for learning; in fact, "American students average 11,700 hours of their lives in a school building from kindergarten to 12th grade" (Hull \& Newport, 2011, in Cheryan, Ziegler, Plaut, Meltzoff, 2014, p. 4). As such, with the classroom milieu being one of the main places students attend, it is critical to understand how the environment can influence the learning process and impact the student's future. To put it another way, a classroom environment should help students in achieving their full potential. Consequently, examining classroom interior design is significant for potential improvements in the education system to enhance students' learning, maximize information retention, and stimulate participation.

"The way color affects our mental and emotional constitution dates to the ancient Egyptians who studied the effects of color on mood and used them to accomplish holistic benefits" (Pomroy, 2019, para. 5). However, the effect of color on a person's state of mind is often overlooked in the schoolroom design. Color still remains a profound factor to consider, as it plays a big role in emotion, efficiency, and learning. For instance, a meta-analysis completed by Jalil, Yunus, Said \& Iqbal (2015), who wrote multiple publications on the learning environment, claims that according to Jacobs \& Hustmyer (1974), Küller, Mikellides \& Janssens (2009), and Kwallek \& Lewis (1990), red has the most arousal effects, however, hidden threats exist to invoke reduction in attention and moderation in perceiving activities. Whereas a study done by Kamaruzzaman and Zawawi (2010), associate professors from the University of Malaya and the University Technology MARA, Malaysia, respectively, concluded that blue color has the most calming effects and has the highest rating for performing in an environment. Thus, wall colors in a classroom produce a milieu that can be a source of stimulation and concentration. Other than students' attention, "vivid color coding may enhance 
short-term memory and improve functional ability" (Cernin, Keller, \& Stoner, 2003 in Kurt \& Osueke, 2014, p. 1); therefore, appropriate color in classroom design is significant for the improvement of learning in an education system as a whole.

From its increasing awareness of the impact of the classroom environment, a number of studies have already proven that the environmental factors within a classroom have an impact on the students from different perspectives. To provide the field with extended information, it is in the best interest to investigate how the physical classroom environment in terms of classroom wall colors stimulates students' attention.

\section{Literature Review}

Considering that one of the most widely debated topics is around nature vs. nurture, one can conclude that the environment has a huge impact on human development such as personality, behavior, and learning. According to Duyan and Unver (2016), professors in the Department of Architecture at the Yildiz Technology University, Turkey, "Stimulus caused from the physical elements of a space affects people's behaviour and attention" (p. 74). In other words, every factor in our environment can be a source of influence on humans, even though it may be difficult to recognize. In terms of education specifically, students spend most of their time studying in a classroom, where they develop themselves to reach their own goals. Assuming one attends kindergarten to the 8th grade, 4-years of high school, and a university (4 years): the average school year is roughly 180 days at 8 hours per day from the age of 6 until 21 years old, that would be 21,600 hours spent in one's respective school building (Howes, 2018).

Despite how much time spent in a classroom, there's a lack of focus on the potential learning contribution of classroom designs and its environment in the process of learning. Charles K. Tanner (2008), a professor in the Department of Career and Information Studies at the University of Georgia, predicted that the major issues facing the influence of school's environment on student's learning are that many classroom environments have been hurriedly constructed in the aim to seek quick solutions for exponentially growing student populations as well as repetition of existing school design. For that reason, white continues to be used as a traditional and safe choice for classroom walls (Grube, 2013). Although the color of white is often referred to as the natural color and widely accepted for its professional quality, many people are unaware of its concealed effect (Kwallek \& Lewis, 1990; Stone, 2001, in Jalil, Yunus, Said, 2012). As a matter of fact, Jalil, Yunus, and Said (2012) showed a series of studies that exhibit a minimization in performances due to the effect of white color. Additionally, a survey conducted by Kurt, an associate professor in the Department of Architecture at Cyprus International University, Nicosia, and Osueke (2014), from the Zedrock and Herman Architecture, Nigeria, demonstrated that the majority of the college students perceived white color on walls as boring and uninteresting. In essence, white walls may have a detrimental influence on students' mood and productivity.

In reality, a human eye can distinguish over 7 million colors, at the same time, "a single color can have a series of meanings and interpretations to various people in various regions of the world" (Kurt \& Osueke, 2014, p. 3). Laying eyes on color provokes a specific sensation. For instance, the red color tends to grab people's attention and yields excitement and courage; on the other hand, the color of green functions as emotionally calming to eyes as well as filtering out distractions (Kamaruzzaman \& Zawawi, 2010). In consideration of that, Grube (2013), an internationally accredited color designer, claims that "Proper color usage on classroom walls creates an enriched learning environment that increases student achievement, accuracy, instructor effectiveness, and staff efficiency. An enriched learning environment is one of the keys to successful academic performance and provides a "feel good" atmosphere that can stimulate positive emotion" (p. 219). In short, classroom wall color greatly correlates with students' mental stability in learning, further leading to their learning retention. Besides, Grube (2013) implies a possible solution for classrooms with restricted architectural elements such as low ceilings or absence of windows by incorporating warmer or cooler colors to deliver a comfortable environment. Being in a safe and comfortable learning environment is a prerequisite for generating concentration. Moreover, Grube (2013) declares that using colors on classroom walls is equivalent to having an additional "teacher", which has the power to provide psychological benefits including 
motivation and encouragement for learners. Thus, there should be appropriate color choices in school so that the productivity and concentration within students are well maintained.

In response to Grube's (2013) investigation on how colors on walls link to learning behavior, Duyan and Unver (2016) explored the effect of different wall colors on students' attention utilizing the Bourdon Attention Test. Colors of red, yellow, green, blue, and purple were implemented into third-grade students' classrooms at two elementary schools, and students attended their regular classes for the duration of one week for each color. The Bourdon Attention Test was carried out on the last day of the week (Friday) for five weeks. Consequently, data shows that the attention test scored the highest with the purple wall color, followed by blue, green, yellow, and red wall color as the lowest, though the statistical difference illustrated was very little (p. 77). The uncertainty of a comprehensive conclusion remains to the fact that the results of the attention tests are only dependent on two schools. Nonetheless, Duyan and Unver (2016) concluded that among the five wall colors, purple had the most positive effect on students' attention in both private and state schools. Otherwise speaking, wall colors have essential contributions to the learning environment.

Many studies revealed the significant relationship between colored classroom walls and students' learning. However, there has not been any study based on the students from international schools, where the countries of the schools do not utilize English as a native tongue, but embedded English as a primary language of instruction in the international schools. Furthermore, note that the majority of the studies in this field are based on the results of primary school levels or adults and rather not at the secondary levels. In fact, studies carried out with elementary students asserted that 7-11-year-olds are in a critical stage of learning and processing information (Park, 2014, in Duyan \& Unver, 2016). But once thought thoroughly, as long as the students are in a classroom to learn, each and every one of them is at their essential stage of self-development no matter how old they are. This factor may represent the gap of knowledge which proves that school design should vary depending on the students' age because of the difference in the effect of the classroom environment. Therefore, this study has the necessity to complete its examination of a brandnew perspective of the classroom wall color effect based on eighth-grade students from an international school in Chiang Mai, Thailand. Altogether, the results of this study can provide significant data for those considering to construct a successful classroom environment in the future as well as contributing to broadening perspectives about the importance of classroom environment for students' learning and potential, specifically in an applicable area of classroom wall colors. With the increased knowledge around what may seem to be small changes, it can create a big improvement in the education system that will foster learning for all learners and lead us to a better future.

\section{Methodology}

\section{Selection of Subjects}

The experiment in the current research was carried out in the classrooms of Nakornpayap International School (NIS). In order to prove how classroom wall colors have an impact on students' attention, the researcher decided to conduct a double-blind experiment. Firstly, the participants were grade 8 students at NIS with their ages ranging from 13 to 15 years old. There were a total of 34 participants which consisted of 19 males $(55.9 \%)$ and 15 females (44.1\%). A total of three classrooms were utilized at the same time, where the students were already distributed according to their skill levels in the Thai language usage. In preparation for this experiment, in order to avoid potential confounding variables in the classrooms, the researcher used the same classrooms for both control and experimental conditions and took down any decorating posters (except for ones on the display boards) around the three rooms to set-up a standardized classroom with only the change in wall colors. In addition, the classrooms were already in shape with respect to the recommendation made by the expert advisor, Fazila Duyan, that fittings (tables, chairs, curtains, etc.) and surfaces (ceilings and floors) should be neutral colored in order to maximize the wall color effect. After some small rearrangements, the finalized classrooms are as shown in Figure 1. 
This experiment was held as a double-blind study, where 3 research assistants conducted the Bourdon Attention Tests (one research assistant per classroom). The participants were assigned a number that was presented as a combination of the classroom number and the number of participants in random order. In consideration of performing ethical research, informed consent forms were provided to the sample and read out loud to the students. The students were then asked to sign the informed consent form if they were willing to take part in this experiment. The informed consent form is displayed in Appendix A.

\section{The Control Condition and the Experimental Condition}

In order to measure the effects of colored classroom walls to students' attention, the experiment consisted of two conditions: control and experimental. The control condition reflected the natural classroom environment (white walls, some shelving and cabinets,

a whiteboard and a display board) where the students normally spend their time (see Figure 1), as opposed to the experimental condition that had three different colored corrugated plastic boards

(a)
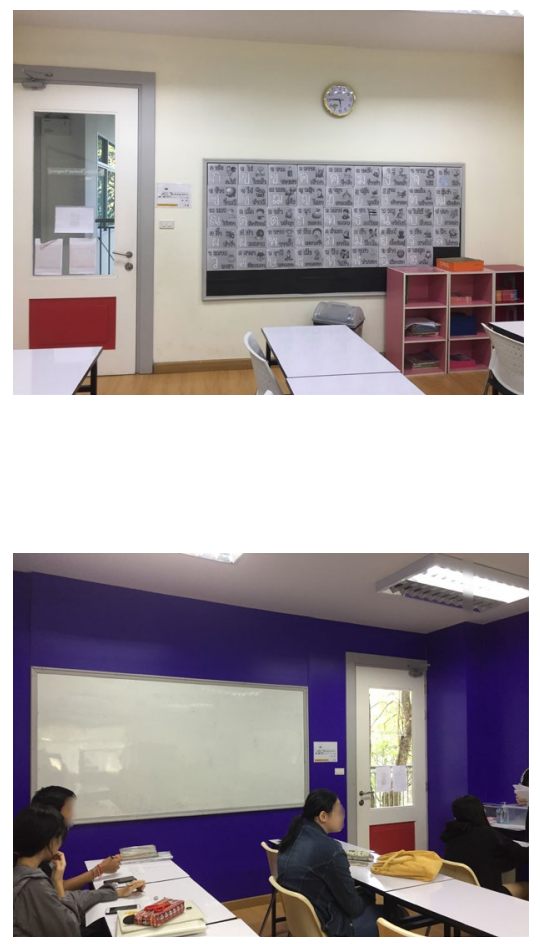

(a)

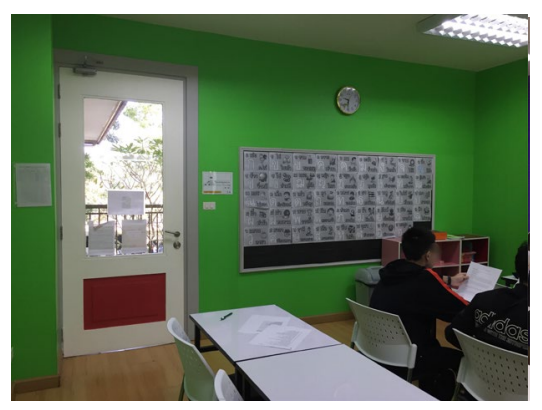

ISSN: 2167-1907 (b)

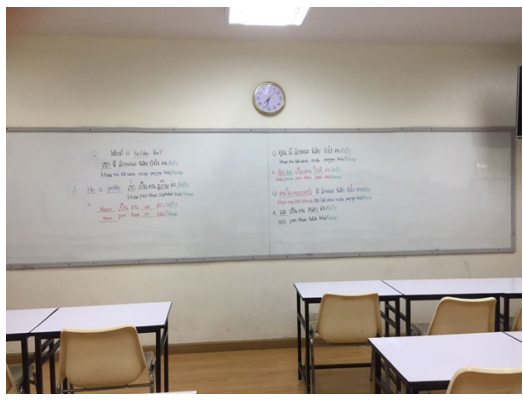

Figure 1. Standardized Classrooms

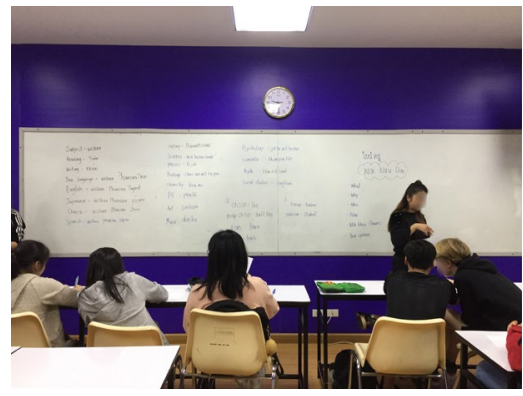

(b)

Figure 2. Purple Classroom Walls
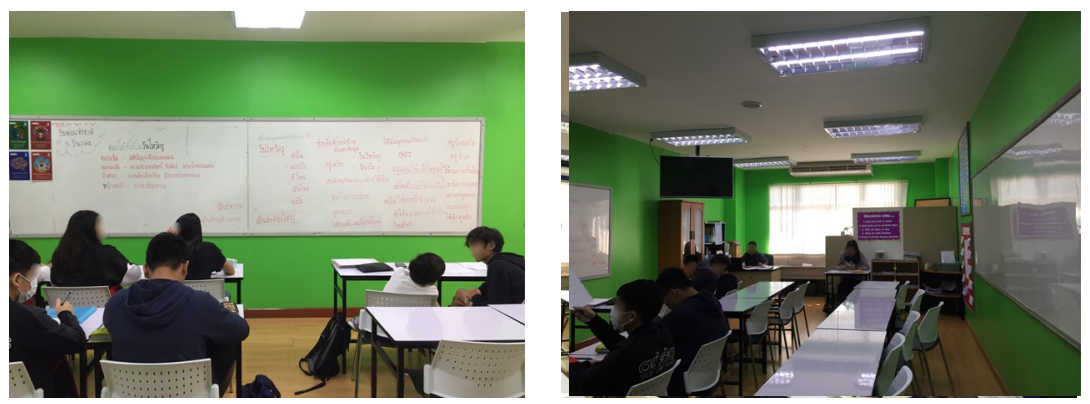
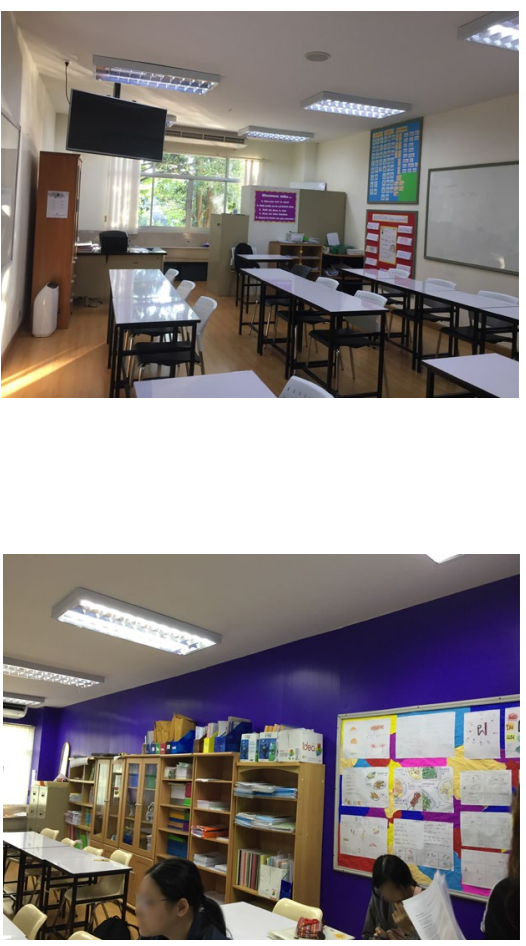

(c) 
(a)

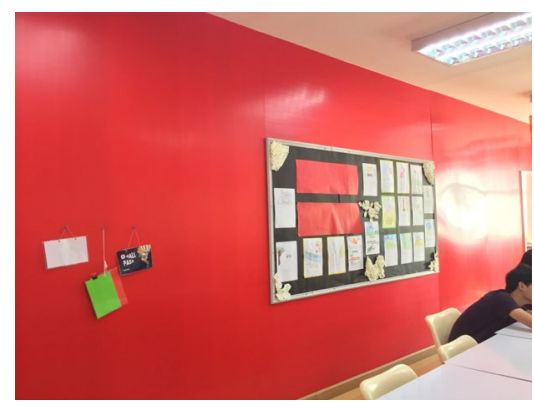

(a) (b)

Figure 3. Green Classroom Walls

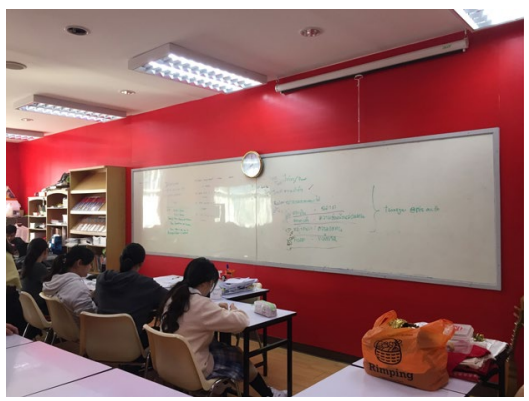

(b) (c)

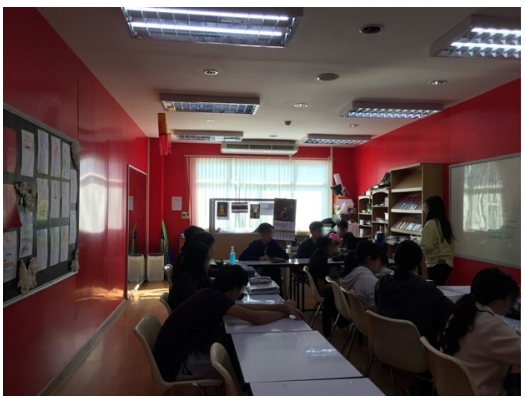

(c)

Figure 4. Red Classroom Walls

implemented onto the classroom walls (see Figures 2, 3, and 4). The school institutional review board decided that the potential side effects of painting the classroom may be too great for students such as the potential smell or toxicity that could come with the paint; therefore, colored corrugated plastic boards were utilized as a replacement of wall paint. Each student spent a total of 15 regular classes (50 minutes per class) in one of the three classrooms for each of the control and experimental conditions. The researcher chose the colors red, green, and purple based on the journal article, "A Research on the Effect of Classroom Wall Colors" by Duyan and Unver (2016). In this study, they assessed the relationship between classroom wall colors and students' attention based on five colors, which were red, yellow, green, blue, and purple. As a result, counting from the least scores of the attention test, the colors were red, yellow, green, blue, and purple. Since there are only three classrooms applicable in this experiment, the researcher selected the bottom, middle, and top from the choices of five colors, which ended up being red, green, and purple.

\section{The Bourdon Attention Test}

In this experiment, the Bourdon Attention Test developed by Benjamin Bourdon (1955) was utilized to measure students' level of attention (see Appendix B). This test was also employed for Duyan's and Unver's (2016) study for the purpose of "[determinating] the effect of attention in terms of cognitive response to classroom wall colour" by incorporating evaluation which could be easily understood and takes as little time consumption (p. 76). The task for this test is to cross out as many groups of four dots found within the time limit of 2 minutes. In an effort to standardize the attention test instructions to all students in the three classrooms, the researcher directed the experiment assistants to read the instructions aloud and to make a brief demonstration by showing an example of how to complete the attention test. Per the expert advisor Fazila Duyan's suggestion, the researcher used different versions of the Bourdon Attention Tests in this study in order to avoid learning effects that could impede on the scores. In this experiment, a total of four Bourdon Attention Tests were given, two in each condition, a pre-test (conducted at the beginning of the first class in the condition), and a post-test (performed at the end of the 15th class in the condition). Thus, the results from each version of the tests will directly reflect the level of attention in each of the conditions. 

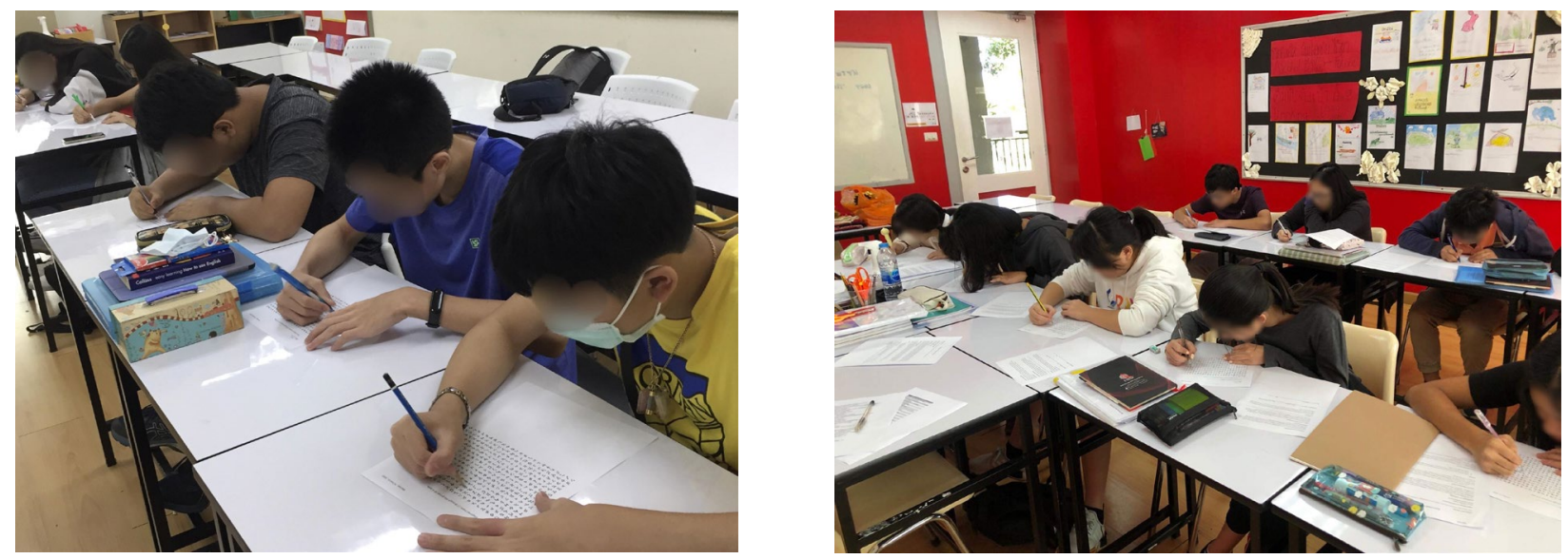

(a)

Figure 5. Application of the Bourdon Attention Test

\section{Evaluation of the data}

Once the data compilation was complete, the attention tests taken by the students corresponding to their participant numbers were handed over to the researcher and were marked manually. The scores were then transferred into a database on Google Sheets, a spreadsheet software program, accordingly.

Further evaluation of the students' attention in different wall color settings was done through a statistical method called paired t-test. A paired t-test is a statistical procedure used to make an inference about the difference between two variables for the same subject (Shier, 2004). For the purposes of the study, this method was used to analyze the impact of classroom wall colors on students' attention in comparison with the original white walls. Additionally, the paired t-test was conducted to investigate the following hypotheses for all colored walls $\left(\mu_{1}\right.$, mean scores of attention tests from the control condition; $\mu_{2}$, those from the experimental condition):

$$
\begin{aligned}
& H_{0}: \mu_{1}=\mu_{2} \\
& H_{a}: \mu_{1} \neq \mu_{2}
\end{aligned}
$$

The null hypothesis states that there are no significant differences in the students' attention level between their control and experimental conditions of the experiment; in short, the colored walls will show no impact at all. In opposition, the alternative hypothesis was set as a two-sided hypothesis where a significant difference in attention level between the control and experimental groups would imply a relationship between the study environment-specifically the wall color-and attention level. The significance level was set at $\alpha<0.05$. This set of hypotheses was developed based on conclusions of studies examining the effects of classroom environment on students' learning. These studies showed a significant correlation between classroom interior design and students' attention. 


\section{Results}

\section{Standardization of Data}

In order to test the hypotheses as mentioned in the methodology, the collected data went through a paired t-test in order to seek the effect of classroom wall colors in comparison with the original white walls. The tabulated collection of data, attention test scores from purple, green, and red classroom walls are reported in Appendix C (Tables 2, 3, and 4 , respectively). Before any applications to this data, some of the data were omitted as a whole due to the participant's absence in at least one of the attention tests of this experiment. To standardize the attention test scores (since each of the attention tests has a different full score), the scores were converted to percentages (\%) for further equivalent evaluation.

\section{Analysis of the Control Condition and the Experimental Condition}

The paired t-test was performed using a graphing calculator (TI-84 Plus CE), and the outputs are as shown in Table 1. At a $5 \%$ significance level $(\alpha=0.05)$, the null hypothesis was rejected for red-colored walls $(p<\alpha)$, thus it can be concluded that there is a statistically significant difference in the students' attention levels between the original environment and the red colored classroom walls. On the other hand, for wall colors of purple and green, it is the researcher that failed to reject the null hypothesis $(p>\alpha)$, implying that purple and green colored walls had no statistically significant impact on students' attention.

\section{Comparing the Effects Between Purple, Green, and Red Wall Colors}

In an extension of Duyan's and Unver's (2016) study, this study compared students' attention levels while visually subjected to each wall color. Because each student has various attention levels in the first place, the mean of the differences between the pre- and the post-test scores from the experimental condition was taken as the source of comparison. As indicated in Figure 6, all three colors showed an increase in students' attention levels. Amongst the three, red wall color recorded the highest increase of attention test scores, followed by green color with a difference of only about $1.5 \%$, and lastly, students in the classroom with purple wall color indicated the least average increase of attention test scores, having less than half the increase of attention test scores from red-colored walls.

Table 1. Results of the Paired t-Test

\begin{tabular}{ccc}
\hline Color & Sample Size (n) & p-value (p) \\
\hline Purple & 12 & 0.4509 \\
Green & 7 & 0.0793 \\
Red & 9 & 0.0156 \\
\hline
\end{tabular}




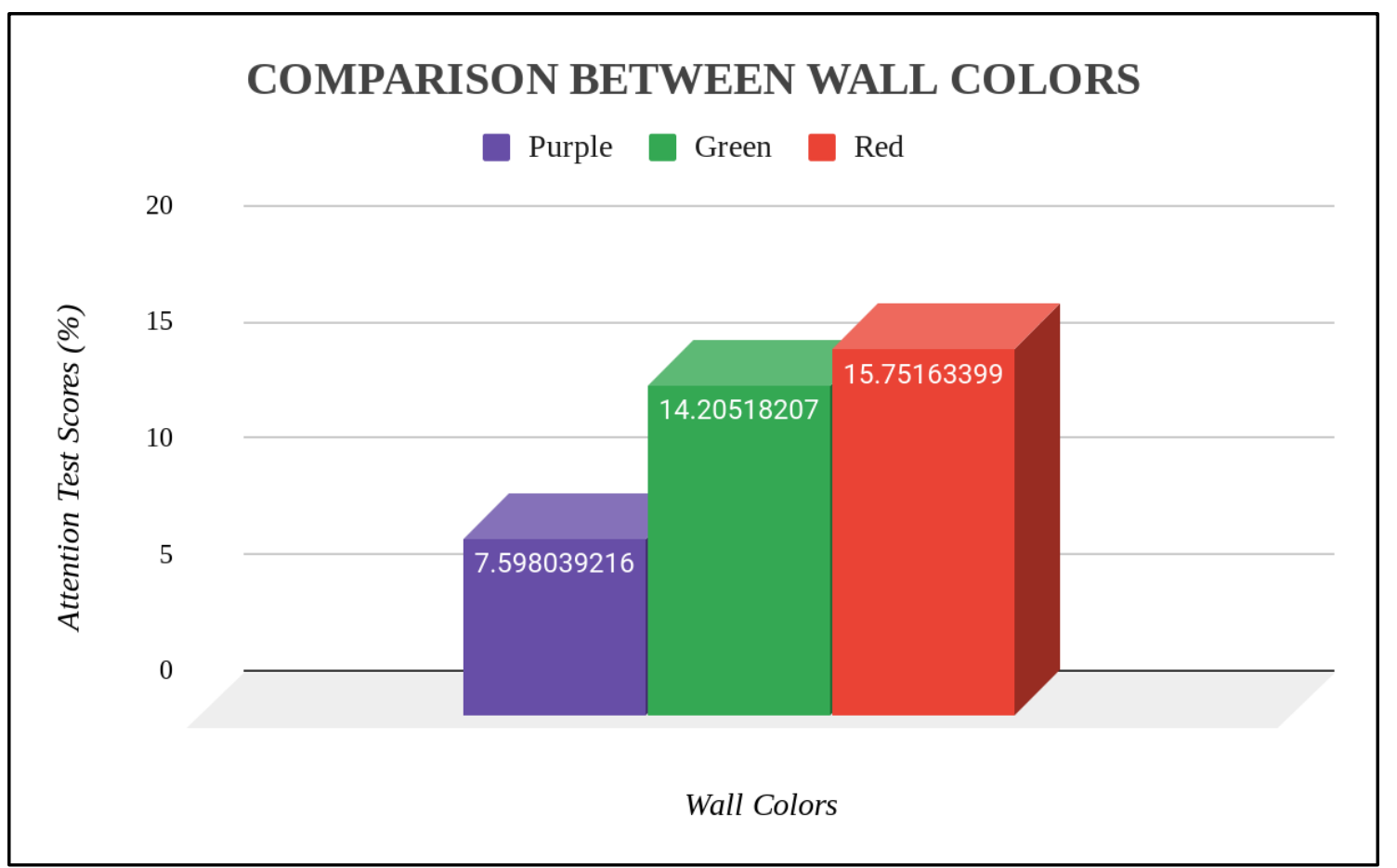

Figure 6. Comparison of Purple, Green, Red Wall Colors

\section{The Difference Between the Pre-Test and the Post-Test}

Furthermore, pre-test and post-test data from the experimental condition were analyzed using the mean values. Figure 7 illustrates the mean scores of students' attention tests taken at the beginning of the implementation of the wall colors compared to those taken after 15 classes in the changed environment. As a result, Figure 7 depicts the averages of post-tests (red columns) exceeding pre-test results (blue columns) in all three wall colors, producing an average difference of $9.79 \%$. This seems to imply that the longer students spent time studying in the classroom with colored walls, the better their attention level became. 


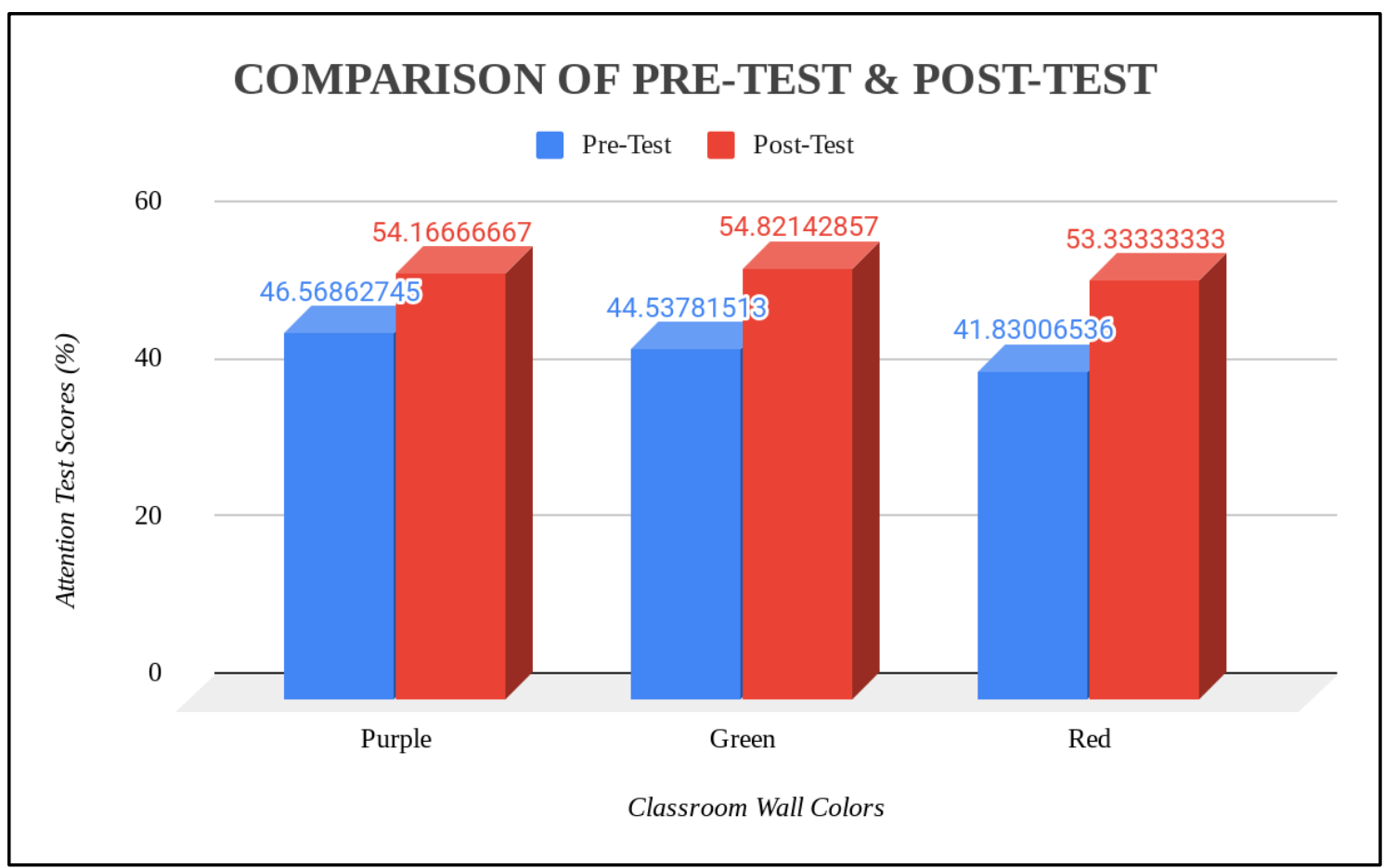

Figure 7. Significance of Difference Between Pre-Test \& Post-Test in the Experimental Condition

\section{Discussion}

In an effort to simulate the design of a classroom environment to promote maximization in student performances, this study investigated the impact of classroom wall colors on eighth-grade students from an international school in Chiang Mai, Thailand. While there exists multiple research that has examined the effect of colored walls, to the best of our knowledge none of these studies have conducted their research based on students from a variety of countries around the globe and share a language that may not be their first language. Drawing upon ideas of the psychological outcomes that colors may offer, it was expected that the participants will show a significant effect on their attention level by the implementation of purple, green, and red colors on the classroom walls. However, the findings indicate that the hypothesized effects were only supported for red classroom walls and not for other wall colors of purple or green. This suggests that red color on classroom walls caused the most stimulation towards students' attention level regardless of whether it was negatively or positively, just based on the results of the paired t-test. While Figure 6 provides a glimpse that the stimulation could be a positive one, other studies argue that it is not. They explain how it could be the cause of avoidance behavior, where colors are found to have a salient negative impact as well (Jalil, Yunus \& Said, 2012). Additional psychological evaluation to determine solid relations between colored environment and human behavior may be needed to further clarify these results.

The comparison between each wall color of purple, green, and red was set to seek the classroom wall color with the most attention level of students. Contrary to prediction, the participants demonstrated the highest attention in their classroom with red-colored walls, on top of green and purple. Taking into account of the big difference between the increase of attention test scores in green and purple walls, the finding is not in line with previous research, as Duyan and Unver (2016) interpreted that "cool wall colors [including purple, blue, and green] affect attention of students at the same level" (p. 77). The disagreement in the results of psychological reactions could point out unanticipated relations among the wall colors by future research. 


\section{Limitations and Future Research}

This study aimed to prove the effect of classroom wall colors on a specific population: eighth-grade students from international schools in Chiang Mai, Thailand. The researcher preferred random sampling, as it remains an ideal technique for unbiased representation of the whole population. However, due to resource and time constraints, eighthgrade students could only be studied from a single school. At this point, the sampling will already fall into the category of biased and non-probability specifically called convenience sampling. Furthermore, while Duyan's and Unver's (2016) study consisted of a total of 78 participants, eighth-grade students at NIS were only 34; it was not enough for additionally conducting random sampling which reduces the sample size significantly. Therefore, the researcher decided to use a sampling technique to get as many participants as possible, but at the same time, protecting the participants' ethics. As a result, they were asked to sign the informed consent form if they accepted the request to be a participant in this experiment. Since the students were asked for a voluntary agreement, this is considered as one of the biased types of sampling called voluntary response sampling.

Other than restrictions regarding the sampling, another limitation of the study was the existence of inescapable factors during the time interval of the experiment. Although avoidable confounding variables (such as posters) were eliminated within the classrooms beforehand, there are other elements that should be considered as it may have interfered with the final results. Firstly, the four attention tests were taken at different times of the day due to the school's class schedule, which was designed to have a rotation of A, B, C, and D days every day consisting of different subjects and at various times. Therefore, the time of day that the attention tests were administered was inconsistent. All of the colors that the human eye detects are a reflection and/or absorption of light on an object (Smith, 2019). Therefore, this could be an interference as the difference of the lighting in the classroom may affect the students' perception of the colored walls. In addition to the various effects of lighting that has to be offered into the classroom throughout the day, the experiment was conducted from January to March, when in Thailand's dry season, farmers intentionally burn their field for clearance and preparation for the next harvest (IQAir, 2020). The level of air quality mostly exceeded an Air Quality Index of 100, some days reaching 200 during the months of February and March (The World Air Quality Project, 2020). Poor air quality would greatly affect student's health, as well as causing detriments to their educational performance (Hogenboom, 2019).

Among the environmental factors mentioned above, they were fairly predictable; however, an unexpected alteration had to be made due to emergent two-week school closure (January 29th - February 10th, 2020). Under concerns of the current situation with influenza and coronavirus in Chiang Mai, NIS concluded to take an aggressive proactive approach to ensure the safety and health of the community. Given that the school shutdown occurred between the pre-test and the post-test of the experimental condition creating a gap for the 15 classes that students must attend for with the colored classroom walls, it can be assumed this may have had an effect on the results. Ultimately, under these circumstances, this research has successfully addressed the goal of attempting to find out how classroom wall colors affect eighth-grade students from an international school in Chiang Mai, Thailand in terms of their attention level.

One avenue for future directions to reduce the research gap has been identified by previous research but has not been extensively studied. From a study by Jalil, Yunus, and Said (2012), they've found that only a few prominent colors have been focused on by researchers, including "red (53\%), blue (30\%), white (25\%) and green (19\%)" (p. 59). Moreover, Duyan's and Unver's (2016) study addressed to research into a wider range of wall colors to improve one's quality of life. Inclusively, assessment based on a variety of wall colors would open up a possibility to detect unidentified responses.

However, decades of reports that have been invested to pursue solutions for improvement in the education system through the design of the built environment are inevitable. In regards to the possession of those studies concretely towards positive aspects, Grube (2013) questions, "why are colored walls not employed as a design standard in the educational facilities...?" (p. 221). Overseeing the relationship between colors on classroom walls and students' academic performances may raise concerns regarding the potential side effects on students due to making sudden 
changes to their learning environment. However, the findings of this study proved that there is a significant increase in the attention test level after taking 15 classes in all three colored classroom walls, which signifies that it is just a matter of time. As supported by Grube (2013), colored walls stimulate students mentally leading to affect physical performances but not to the point where they become harmful. There is still room for improving student's educational conditions to ensure maximized growth in their learning process.

\section{Conclusion}

This study has demonstrated that the color red on classroom walls does significantly contribute to eighth-grade students' attention level, while others of green and purple showed little effect. Beyond the results of the paired t-tests, the findings of comparing purple, green, and red wall colors, as well as attention test scores of pre-test and post-test in the experimental condition, were partly aligned with previous research but also revealed new aspects in the effect of wall color on students' attention. In fact, they are all crucial elements to take part in considerations for future actions. Furthermore, this study is a follow up to initiate a better understanding of why there is a necessity to take into account colored walls for longer spans of concentration in learning. With regards to the findings of previous studies that asserted the different responses people give based on their culture, this study opened up a new perspective of students from an international school, where diversity is not only limited to culture. While there are countless students in the world, it is imperative that future research is conducted based on a variety of students and a wider spectrum of wall colors for future reference to designers to resemble the most suitable colored environment. With further investigation, a conducive learning environment will benefit performances and well-being for future generations.

\section{Acknowledgments}

Much appreciation goes to the full support of teachers, staffs, students, and colleagues from Nakornpayap International School, which made this research not only possible, but also successful.

\section{References}

Cernin, P. A., Keller, B. K., \& Stoner, J. A. (2003). Color Vision in Alzheimer's Patients: Can We Improve Object Recognition with Color Cues? Aging, Neuropsychology, and Cognition, 10(4), 255-267. https://doi.org/10.1076/anec.10.4.255.28971

Cheryan, S., Ziegler, S. A., Plaut, V. C., \& Meltzoff, A. N. (2014). Designing Classrooms to Maximize Student Achievement. Policy Insights from the Behavioral and Brain Sciences, 1(1), 4-12.

https://doi.org/10.1177/2372732214548677

Duyan, F., \& Ünver, R. (2016). A Research on the Effect of Classroom Wall Colours on Student's Attention. A/Z: ITU Journal of Faculty of Architecture, 13(2), 73-78. https://doi.org/10.5505/itujfa.2016.57441

Grube, K. (2013). The Color on the Wall. American School \& University, 86(3), 219-221. http://search.ebscohost.com/login.aspx?direct=true \&db=asn\&AN=92706263\&site=ehost-live

Hogenboom, M. (2019, April, 19). How Air Pollution is Doing More Than Killing Us. BBC Future. https://www.bbc.com/future/article/20190415-how-air-pollution-is-doing-more-than-killing-us

Howes, B. (2018, September, 5). Who Knew?! The Howes Group. https://thehowesgroup.com/who-knew-time/? 
Infrastructure Solutions Group. (2013, December 1). Coloring the Classroom. Spaces4learning: Impacting K-12 \& Higher-Education Environments. https://spaces4learning.com/Articles/2013/12/01/Coloring-the-Classroom

IQAir. (2020, April 21). Retrieved April 21, 2020, from https://www.iqair.com/th-en/thailand/chiang-mai

Jalil, N. A., Yunus, R., Said, N. S., \& Iqbal, M. I. (2015). Color Effect on Physiology in Stimulating Environment. Pertanika Journal of Social Sciences and Humanities (JSSH), 1-18. https://doi.org/10.13140/RG.2.1.1866.0565

Jalil, N. A., Yunus, R., \& Said, N. S. (2012). Environmental Colour Impact upon Human Behaviour: A Review. Procedia - Social and Behavioral Sciences, 35, 54-62. https://doi.org/10.1016/j.sbspro.2012.02.062

Kamaruzzaman, S. N. \& Zawawi, E. M. A. (2010). Influence of Employees’ Perceptions of Colour Preferences on Productivity in Malaysian Office Buildings. Journal of Sustainable Development, 3(3), 283-293. http://www.ccsenet.org/jsd

Kurt, S., \& Osueke, K. K. (2014). The Effects of Color on the Moods of College Students. SAGE Open, 1-12. https://doi.org.10.1177/2158244014525423

Kwallek, N., \& Lewis, C. M. (1990). Effects of Environmental Colour on Males and Females: A Red or White or Green Office. Applied Ergonomics, 21(4), 275-278. http://doi.org.10.1016/0003-6870(90)90197-6

Marchand, G. C., Nardi, N. M., Reynolds, D., \& Pamoukov, S. (2014). The Impact of the Classroom Built Environment on Student Perceptions and Learning. Journal of Environmental Psychology, 40, 187-197. http://dx.doi.org/10.1016/j.jenvp.2014.06.009

Maxwell, L. E. (2010). Chaos Outside the Home: The School Environment. In G.W. Evans \& T.D. Wachs (Eds.), Decades of Behavior (Science Conference). Chaos and its Influence on Children's Development, 83-95. https://doi.org/10.1037/12057-006

Park, J. G. P. (2014). Correlations Between Color Attributes and Children's Color Preferences. Wiley Periodicals, Inc. Col Res Appl, 39(5), 452-462. https://doi.org/10.1002/col.21801

Pomroy, Kathryn. (2019, June 28). Introduction to the Psychology of Color: For Interior Designers. The Art Career Project. https://www.theartcareerproject.com/psychology-of-color-interior-design/

Shier, R. (2004). Statistics: 1.1 Paired t-tests. Mathematics Learning Support Centre. 1-3. http://www.statstutor.ac.uk/resources/uploaded/paired-t-test.pdf

Smith, Kate. (2019). How Light Affects Color. Sensational Color. Retrieved April 23, 2020, from https://www.sensationalcolor.com/light-affects-color/

Stone, N. J. (2001). Designing Effective Study Environments. Journal of Environmental Psychology, 21(2), 179190. https://doi.org/10.1006/jevp.2000.0193

Tanner, C. K. (2008). Explaining Relationships Among Student Outcomes and the School's Physical Environment. Journal of Advanced Academics, 19(3), 444-471. https://doi.org/10.4219/jaa-2008-812 
The World Air Quality Project. (2020, April 21). Chiang Mai Air Pollution: Real-time Air Quality Index (AQI). Retrieved April 21, 2020, from https://aqicn.org/city/chiang-mai/ 